\title{
Acute effect of passive cycloergometry on the cardiovascular system and respiratory mechanics of critically ill patients: a randomized controlled trial
}

Efeito agudo da cicloergometria passiva sobre o sistema cardiovascular e a mecânica respiratória de pacientes críticos: um estudo controlado e randomizado

Efecto agudo de la cicloergometría pasiva sobre el sistema cardiovascular y la mecánica respiratoria de pacientes críticos: un estudio controlado y aleatorizado

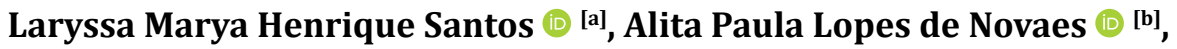

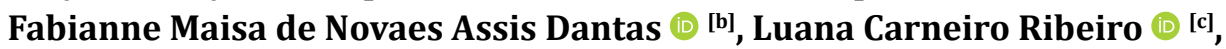
Célia Maria Machado Barbosa de Castro ${ }^{[1]}[$, Eduardo Eriko Tenório de França $₫$ [e]

\footnotetext{
[a] Universidade Católica de Pernambuco (Unicap), Recife, PE, Brazil

[b] Hospital das Clínicas (HC), Recife, PE, Brazil

[c] Hospital Agamenon Magalhães, Recife, PE, Brazil

[d] Universidade Federal de Pernambuco (UFPE), Recife, PE, Brazil

[e] Universidade Federal da Paraíba (UFPB), João Pessoa, PB, Brazil
}

\section{Abstract}

Introduction: The rehabilitation of critical patients usually occurs in the bed and is classified as low cardiovascular intensity. Therefore, it is essential to understand the physiological effects of these resources that we apply in clinical practice. Objective: Evaluate the acute effect of passive cycloergometry of lower limbs on respiratory

\footnotetext{
* LMHS: BS, e-mail: marya_laryssa@live.com APLN: MS, e-mail: alitanovaes@gmail.com FMNAD: PhD, e-mail: fabianneassis@gmail.com LCR: MS, e-mail: crluana@icloud.com CMMBC: PhD, e-mail: cmmbc5@yahoo.com.br EETF: PhD, e-mail: edueriko@hotmail.com
} 
mechanics and cardiovascular parameters in critically ill patients. Method: This was a labeled, randomized, controlled trial conducted in two intensive care units in the city of Recife, between August 2016 and May 2017. Patients were divided into two groups: (i) passive cycloergometry group $(n=16)$, where the patient performed a lower limb cycloergometry session for 20 minutes, and (ii) control group $(n=14)$, where the patient did not perform any therapeutic intervention, except during the application of the protocol. Cardiovascular parameters and respiratory mechanics were evaluated before, during and after their applicability. Results: No demographic differences were found between the two groups, showing the homogeneity between them. Regarding cardiovascular parameters, there were no differences between groups before, during and after the protocol. Regarding respiratory mechanics, there was a slight elevation of the resistance of the respiratory system in the cycloergometry group and a reduction of the same in the control group. Conclusion: The results suggest that passive cycloergometry applied to the critical patient did not promote significant cardiovascular changes and respiratory mechanics, being considered a safe and effective technique in clinical practice that can be applied without causing harm to patients under mechanical ventilation.

Keywords: Exercise Therapy. Intensive Care Unit. Respiratory Mechanics.

\section{Resumo}

Introdução: A reabilitação de pacientes críticos geralmente ocorre no leito e é classificada como de baixa intensidade cardiovascular. Portanto, é essencial conhecermos os efeitos fisiológicos dos recursos que aplicamos na prática clínica. Objetivo: Avaliar o efeito agudo da cicloergometria passiva de membros inferiores sobre a mecânica respiratória e parâmetros cardiovasculares em pacientes críticos. Método: Trata-se de um ensaio clínico, randomizado, controlado, realizado em duas unidades de terapia intensiva na cidade de Recife, entre agosto de 2016 e maio de 2017. Os pacientes foram divididos em dois grupos: grupo cicloergometria passiva $(n=16)$ : o paciente realizou uma sessão de cicloergometria de membros inferiores durante 20 minutos; e grupo-controle $(n=14)$ : não realizou nenhuma intervenção terapêutica, apenas durante a aplicação do protocolo. Foram avaliados os parâmetros cardiovasculares e a mecânica respiratória, antes, durante e após a sua aplicabilidade. Resultados: Não foram encontradas diferenças demográficas entre os dois grupos estudados, mostrando a homogeneidade entre eles. Em relação aos parâmetros cardiovasculares, não houve diferença entre os grupos antes, durante e após o protocolo. Com relação à mecânica respiratória houve uma discreta elevação da resistência do sistema respiratório no grupo cicloergometria e uma redução da mesma no grupo-controle. Conclusão: Os resultados sugerem que a cicloergometria passiva aplicada ao paciente crítico não promoveu alterações cardiovasculares e na mecânica respiratória significativas, sendo considerada uma técnica segura e eficaz na prática clínica, podendo ser aplicada sem causar prejuízos aos pacientes sob ventilação mecânica.

Descritores: Terapia por Exercício. Unidade de Terapia Intensiva. Mecânica Respiratória.

\section{Resumen}

Introducción: La rehabilitación de pacientes críticos generalmente ocurre en el lecho y se clasifica como de baja intensidad cardiovascular. Por lo tanto, es esencial conocer los efectos fisiológicos de estos recursos que aplicamos en la práctica clínica. Objetivo: Evaluar el efecto agudo de la cicloergometría pasiva de miembros inferiores sobre la mecánica respiratoria y parámetros cardiovasculares en pacientes críticos. Método: Se trata de un ensayo clínico, aleatorizado, controlado, realizado en dos unidades de cuidados intensivos en la ciudad de Recife, entre agosto de 2016 y mayo de 2017. Los pacientes fueron divididos en dos grupos: grupo cicloergometría pasiva ( $n=16)$ : el paciente realizó una sesión de cicloergometría de miembros inferiores durante 20 minutos; y grupo control $(n=14)$ : no realizó ninguna intervención terapéutica, sólo durante la aplicación del protocolo. Se evaluaron los parámetros cardiovasculares y la mecánica respiratoria, antes, durante y después de su aplicabilidad. Resultados: No se encontraron diferencias demográficas entre los dos grupos estudiados, mostrando la homogeneidad entre ellos. En relación a los parámetros cardiovasculares, no hubo diferencia entre los grupos antes, durantey después del protocolo. Con respecto a la mecánica respiratoria, hubo una discreta elevación de la resistencia del sistema respiratorio en el 
grupo cicloergometría y una reducción de la misma en el grupo control. Conclusión: Los resultados sugieren que la cicloergometría pasiva aplicada al paciente crítico no promovió significativas alteraciones cardiovasculares y en la mecánica respiratoria, siendo considerada una técnica segura y eficaz en la práctica clínica, pudiendo ser aplicada sin causar perjuicios a los pacientes bajo ventilación mecánica.

Descriptores: Terapia por Ejercicio. Unidades de Cuidados Intensivos. Mecánica Respiratoria.

\section{Introduction}

Early mobilization in the intensive care unit (ICU) has shown numerous benefits [1]. However, the literature is inconclusive about the specific effects on muscle strength and functional capacity, with some studies showing opposite effects [2-4].

Despite advances in early rehabilitation, one in two patients develops muscle weakness [5]. These contrasting results are probably due to the fact that most of the exercises performed in the first hours of ICU stay are of low cardiovascular intensity, since the patient remains restricted to bed [5-8]. Rehabilitation is limited by the presence of the endotracheal tube, sedation, a state of mental confusion, among other factors $[9,10]$.

Many exercise techniques can be performed in bed, including passive cycloergometry, which has been increasingly used in clinical practice, and showing a safe and well tolerated method when used in critical patients [11]. However, its repercussions on the cardiovascular system and lung function in intubated patients have not yet been evaluated.

In general, the goal of the exercise is to increase or maintain muscle strength and cardiovascular function. In exercise physiology, cardiac output has been shown to increase linearly, from rest to maximum effort, and is one of the main responses to reflect exercise intensity [12-14].

Thus, one method of assessing exercise intensity is to measure cardiovascular parameters and muscle oxygenation. Theoretically, the greater the intensity of the exercise, the higher the heart rate (HR) and the maximum oxygen consumption [12-15]. This increase in metabolism during exercise also occurs in critically ill patients [16]. Another aspect to be considered is the relationship between the intensity of the exercise performed in bed and its impact on the respiratory mechanics of critical patients, which will directly reflect the pulmonary function of mechanically ventilated patients [17-20].
Therefore, this study aims to evaluate the acute effect of passive cycloergometry of lower limbs on cardiovascular parameters and respiratory mechanics in intubated and sedated, bed restricted patients in order to determine the impact of this type of activity on critical patients.

\section{Methods}

\section{Drawing}

This is a randomized controlled clinical trial conducted in two general ICUs in the city of Recife, between August 2016 and May 2017. This study is part of the research project entitled Effect of exercise and electrical stimulation on the critical patients immune system, CAAE number: 04563612.5.0000.5197 and approved under No. 61991 by the Institutional Review Board of the Research Ethics Committee of the Agamenon Magalhães Hospital. The study complies with the Declaration of Helsinki and consent was given in writing by the patient's legal guardian. The study protocol was published in the Brazilian Registry of Clinical Trials (BReCT) under No. RBR-6pxpx9 on September 21, 2018, retrospectively and met the Consolidated Standards of Reporting Trials (Consort) guidelines for clinical trials.

\section{Patients}

Inclusion criteria were clinical patients admitted to the general ICU, aged over 21 years, intubated for at least 24 hours, under mechanical ventilation (MV), sedated with the Richmond Agitation-Sedation Scale (Richmond Agitation-Sedation Scale - RASS) between $(-3)$ and $(-5)$, with a good cardiac reserve, demonstrated by a variability lower than $20 \%$ of resting HR, systolic blood pressure (SBP) between $90 \mathrm{mmHg}$ and $180 \mathrm{mmHg}$, normal electrocardiogram, peripheral capillary oxygen saturation (Sp02) greater than $90 \%$, inspired oxygen fraction (FiO2) lower than $60 \%$, respiratory rate (RR) lower than $25 \mathrm{ipm}$, 
hemoglobin greater than $7 \mathrm{~g} / \mathrm{dL}$, platelets greater than 20,000 cells $/ \mathrm{mm} 3$ and no diagnosis of sepsis.

Exclusion criteria were patients who could not walk without assistance before ICU admission, patients using beta-blockers, high-dose vasoactive drugs, pregnant women, patients with body mass index (BMI) greater than $35 \mathrm{~kg} / \mathrm{m}^{2}$, previously diagnosed with neuromuscular and vascular disease, history of stroke and unconsolidated fracture.

\section{Sample calculation}

We performed the sample size calculation with the WinPepi program (PEPI-for-Windows), where the following criteria were considered: $95 \%$ confidence interval and five percentage points sampling error. Considering an average of the previous two years of 385 patients intubated for the study period and that not all of these patients underwent lower limb cycloergometry [21], taking into account a sample loss of $20 \%$, a minimum sample of 28 patients has been totaled.

\section{Evaluation}

Initial assessment was performed using data from medical records such as clinical history, diagnosis, Acute Physiology and Chronic Health Evaluation Classification System II (Apache II) score, BMI, use of neuromuscular blockers, sedatives and vasoactive drugs. We studied clinical patients of both genders on MV divided into 2 groups. The order of interventions for one of the two groups was randomized using the www.random.org program. The control group did not undergo therapeutic intervention during the study period, but underwent conventional physiotherapy in all other ICU stays. The lower limb passive cycle ergometry group performed lower limb ergometry using the cycle ergometer (Flex Motor with sensor; Cajumoro; Bragança Paulista; São Paulo, Brazil) with 30 rotations programmed per minute for 20 minutes (Figure 1) [22].

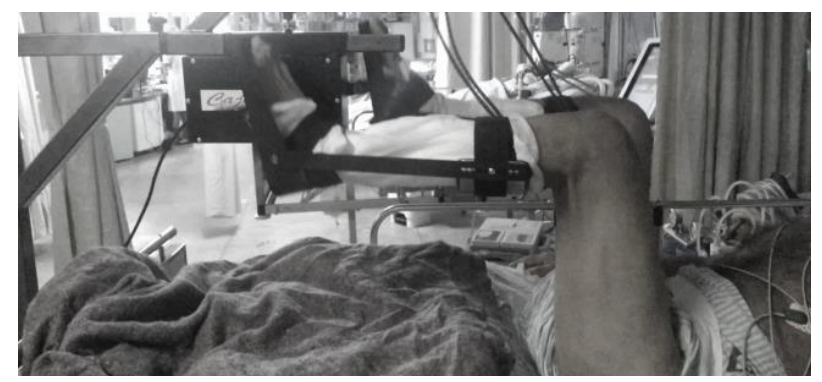

Figure 1 - Illustration of the application of lower limb cycloergometry in critically ill patients' mechanical ventilation.
The group undergoing passive cycle ergometry within 20 minutes was monitored for respiratory mechanics before, immediately after, 10 and 30 minutes after using the cycle ergometer. To obtain the respiratory mechanics parameters, patients were placed in volume-controlled ventilation mode, with a tidal volume of $6 \mathrm{ml} / \mathrm{kg}$ predicted weight, obtained through the formula for men $(M)=50+0.91(h-152.4)$ for males and females $(F)=45.5+0.91(h-152.4)$ for females. The acquired result of the above formulas was multiplied by $6 \mathrm{ml} / \mathrm{kg}$. Then, a pause at the end of inspiration was performed for approximately 2-3 seconds to obtain the plateau pressure (Pplateau). Through the Plateau Pressure value, it was possible to calculate the static compliance (Cst) of the respiratory system through the formula Cst $=$ VC/Pplateau - PEEP, as well as the respiratory system resistance (Rsr) through the Rsr $=$ Ppeak - Pplateau/Flow, where PEEP means positive end-expiratory pressure. This same group was also monitored for cardiovascular parameters, namely: HR, RF, SBP, DBP and MAP before the start of the protocol, every 3 minutes after application, and after 10 and 30 minutes after use.

Patients in the control group had all these variables evaluated during the same period as the group that did passive lower limb cycle ergometry. However, the control group did not perform any intervention.

\section{Statistical analysis}

Statistical analysis was performed using GraphPadPrism 4 software. Continuous data were expressed as mean and standard deviation. To test their assumption of data normality, the Shapiro-Wilk test was applied. The comparison between the mean of the two groups was performed using repeated measures Anova tests with Tukey post-test and t-test for parametric variables. All conclusions were made at a significance level of $5 \%$, within a confidence interval of $95 \%$

\section{Results}

Forty patients with pathologies of various etiologies participated in the initial phase of the research, of which 10 met the exclusion criteria of the study, but of these, only 30 patients completed their analysis, distributed as follows: control group $(n=14)$ and cycloergometry group $(n=16)$ (Figure 2$)$. 
Figure 2 - Flowchart of the study design.
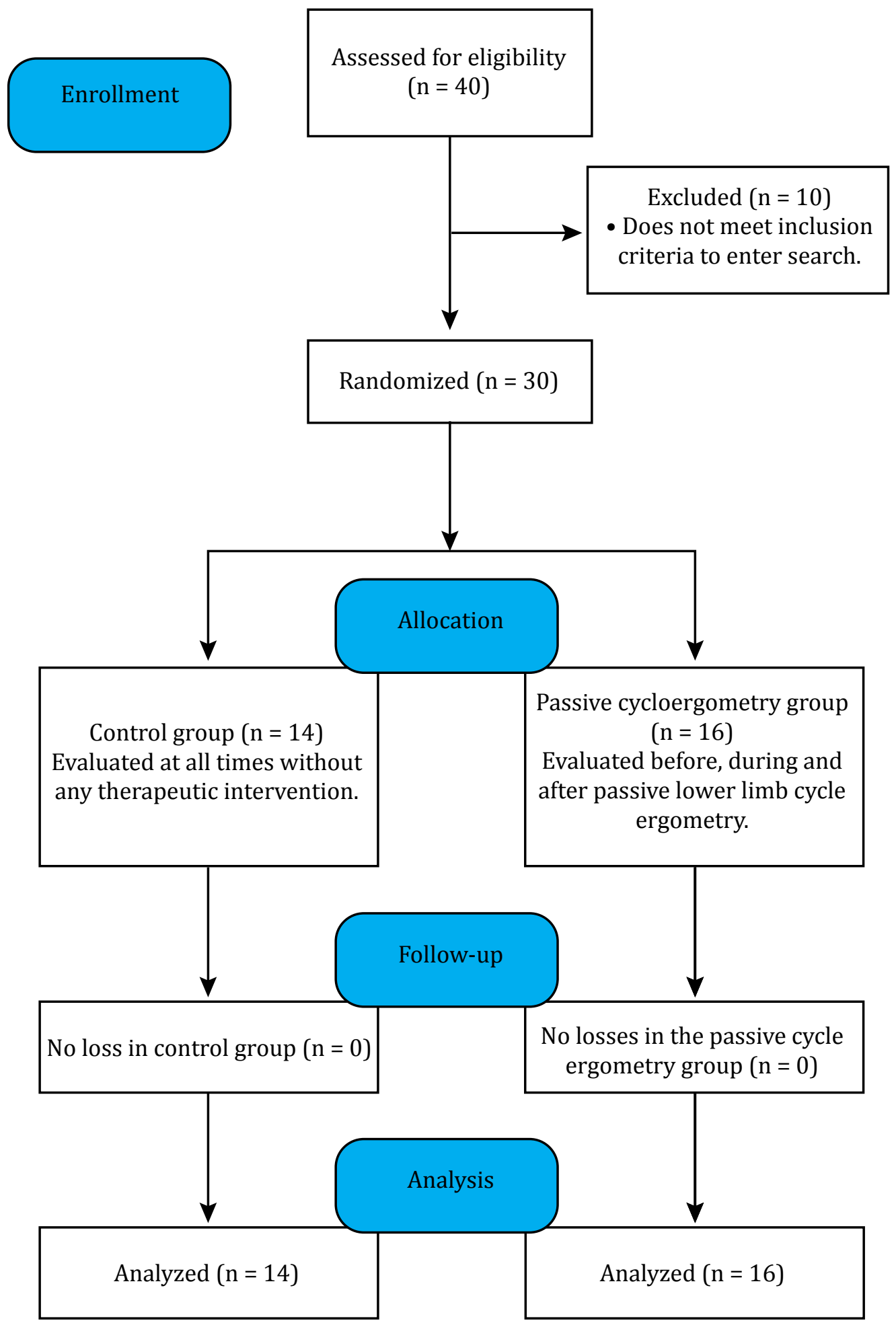

During the study period, data from $30 \mathrm{MV}$ patients admitted to the ICU were analyzed. The mean age of the cycle ergometry group was of $61.19 \pm 18.2$ years, while the control group was $55.7 \pm 15.2$ years. Table 1 shows the demographic characteristics of the sample in the groups' comparison, both of which were homogeneous with each other. No differences were observed between age, height, weight, BMI, water balance (WB) values in the last 24 hours, sedation scale, RASS score, Apache II score, MV time and ICU time. 
Table 1 - Sample's demographic characteristics

\begin{tabular}{lccc}
\hline \multicolumn{1}{c}{ Variables } & Control Group $(\mathbf{n}=\mathbf{1 4})$ & PC Group $(\mathbf{n}=\mathbf{1 6})$ & p-value \\
\hline Age (years) & $55.7 \pm 15.2$ & $61.19 \pm 18.20$ & $\mathbf{0 . 2 3 ^ { * }}$ \\
Height (cm) & $166.9 \pm 6.7$ & $163.0 \pm 6.9$ & $\mathbf{0 . 1 3 ^ { * * }}$ \\
Weight (kg) & $69.5 \pm 13.2$ & $68.56 \pm 11.5$ & $\mathbf{0 . 8 4 ^ { * * }}$ \\
BMI (kg/cm²) & $24.5 \pm 4.2$ & $28.08 \pm 9.4$ & $\mathbf{0 . 1 6 ^ { * }}$ \\
WB-24h (ml) & $1188 \pm 1075$ & $1084 \pm 1050$ & $\mathbf{0 . 7 9 ^ { * * }}$ \\
RASS & $--4.4 \pm 0.8$ & $-4.2 \pm 0.6$ & $\mathbf{0 . 7 1 ^ { * }}$ \\
Apache II & $22.60 \pm 4.22$ & $22.67 \pm 8.36$ & $\mathbf{0 . 8 8 ^ { * }}$ \\
MV time (days) & $4.14 \pm 2.6$ & $6.0 \pm 3.2$ & $\mathbf{0 . 0 8 ^ { * }}$ \\
UCl time (days) & $4.42 \pm 2.8$ & $7.56 \pm 7.7$ & $\mathbf{0 . 2 0 ^ { * }}$ \\
\hline
\end{tabular}

Note: *Anova: test repeated measures and post Tukey test; **t test; BMI: body mass index; RASS: Richmond Agitation and Sedation Scale; WB: water balance in the last 24 hours; Apache Il: Acute Physiology and Chronic Health Evaluation Classification System II; CP: passive cycloergometry.

Table 2 shows the static compliance data and respiratory system resistance measured before, immediately after the end of the protocol, and at 10 and $30 \mathrm{~min}$ after the application of passive cycle ergometry in both $\mathrm{PC}$ and control groups. The analyses show a reduction in the respiratory system resistance in the control group when comparing the moment before with the immediately after in the control group. For the cycle ergometry group we observed an increase in respiratory system resistance when comparing the moment before with 10 min after the end of the use of passive lower limb cycle ergometry.

Table 2 - Respiratory system compliance and resistance values in the control and passive cycle ergometry (PC) groups

\begin{tabular}{|c|c|c|c|c|c|}
\hline \multicolumn{6}{|c|}{ Respiratory system compliance (Cst.) } \\
\hline & $\begin{array}{l}\text { Cst. before } \\
\left(\mathrm{ml} / \mathrm{cmH}_{2} \mathrm{O}\right)\end{array}$ & $\begin{array}{l}\text { Cst. after } \\
\left(\mathrm{ml} / \mathrm{cmH}_{2} \mathrm{O}\right)\end{array}$ & $\begin{array}{l}\text { Cst. } 10 \mathrm{~min} \\
\left(\mathrm{ml} / \mathrm{CmH}_{2} \mathrm{O}\right)\end{array}$ & $\begin{array}{l}\text { Cst. } 30 \text { min } \\
\left(\mathrm{ml} / \mathrm{cmH}_{2} \mathrm{O}\right)\end{array}$ & $p$ value ${ }^{\dagger}$ \\
\hline Control Group & $38.38 \pm 14.6$ & $41.65 \pm 18,5$ & $41.73 \pm 18.2$ & $41.73 \pm 18.2$ & 0.51 \\
\hline PC Group & $29.56 \pm 11.3$ & $29.87 \pm 13.4$ & $29.33 \pm 10.5$ & $29.33 \pm 10.5$ & 0.96 \\
\hline \multicolumn{6}{|c|}{ Respiratory system resistance (Rsr.) } \\
\hline & $\begin{array}{l}\text { Rsr. before } \\
\left(\mathrm{cmH}_{2} \mathrm{O} / \mathrm{L} / \mathrm{s}\right)\end{array}$ & $\begin{array}{c}\text { Rsr. after } \\
\left(\mathrm{cmH}_{2} \mathrm{O} / \mathrm{L} / \mathrm{s}\right)\end{array}$ & $\begin{array}{l}\text { Rsr. } 10 \text { min } \\
\left(\mathrm{cmH}_{2} \mathrm{O} / \mathrm{L} / \mathrm{s}\right)\end{array}$ & $\begin{array}{l}\text { Rsr. } 30 \text { min } \\
\left(\mathrm{cmH}_{2} \mathrm{O} / \mathrm{L} / \mathrm{s}\right)\end{array}$ & $p$ value $^{\dagger}$ \\
\hline Control Group & $14.15 \pm 6.2$ & $12.08 \pm 4.4^{\ddagger}$ & $13.5 \pm 6.0$ & $12.69 \pm 5.1$ & 0.03 \\
\hline PC Group & $13.61 \pm 5.4$ & $14.41 \pm 5.6$ & $14.71 \pm 5.9^{\ddagger}$ & $13.88 \pm 5.8$ & 0.01 \\
\hline
\end{tabular}

Note: *Anova test repeated measures and post Tukey test; ${ }^{* \star}$ Difference with before; PC: passive cycle ergometry; Cst: static compliance; Rsr: respiratory system resistance; min: minutes.

Table 3 shows no difference for the variables RR, HR, SBP and DBP measured before, soon after the end of the protocol, and at 10 and 30min after the application of passive cycle ergometry and in the control group. 


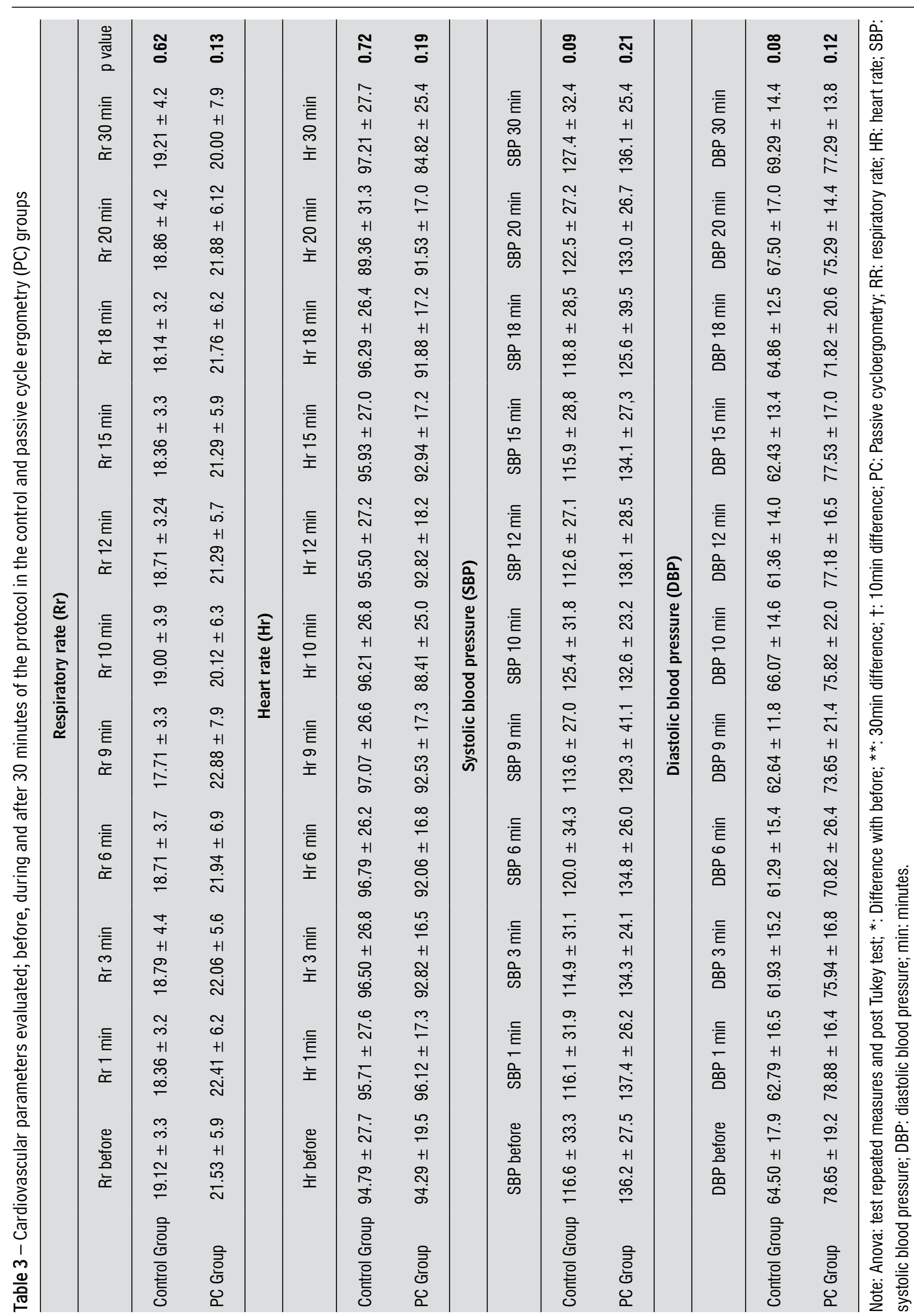




\section{Discussion}

The present study showed that the passive exercise performed in bed was of low intensity and induced a low level of muscle work, not sufficient to cause significant changes in the cardiovascular parameters and respiratory mechanics of intubated patients. We observed a slight increase in the respiratory system resistance in the group of patients undergoing passive cycle ergometry 10 minutes after its application, which may be justified by an increase in the movement of secretions during this type of activity.

The use of passive cycloergomatria as an intervention in the intensive care setting has been shown to be effective and safe in clinical practice, although there are gaps in the literature and recurring doubts from professionals regarding its effects on the possible interference with cardiovascular respiratory response mechanics of patients undergoing this type of intervention. Scientific evidence confirms several beneficial effects of passive limb mobilization, such as attenuating generalized muscle weakness, maintaining a range of motion and improving individual functionality $[23,24]$.

In Table 2, we analyzed the static compliance and resistance of the respiratory system at different times, showing a slight increase in resistance 10 minutes after the end in the cycle ergometry group and reduction soon after in the control group, which in clinical practice this type of minimal change does not represent any harm to respiratory mechanics. These results demonstrate that the use of passive cycloergomatrics in the ICU as a form of intervention is safe without possible risks to respiratory mechanics for bed-restricted patients [11].

Machado et al. [25] when analyzing the effect of passive cycle ergometry on muscle strength, MV time and hospital stay, concluded that only the peripheral muscle strength assessed by the Medical Research Council (MRC) strength score was higher in the passive cycle ergometry group compared to the group undergoing conventional physical therapy.

In another study, Kho et al. [26] used the cycloergometer in 181 patients to analyze its viability and safety in the ICU, and the results confirm its usefulness in clinical practice, without adverse risks to patients. Although there are no previous studies on the assessment of changes in respiratory mechanics during the use of passive cycle ergometry, the safety of the technique in several other parameters has been evaluated. Our study, along with others allow to clarify and add that respiratory mechanics is little affected with the technique, thus justifying its use in patients with borderline respiratory mechanics.

The behavior analysis of RR, HR, SBP and DBP, presented in Table 3, in the period before, every three minutes of the protocol, at the end of therapy, and 10 and 30 minutes after the cycle ergometry, did not show differences between the groups for these evaluated parameters. Our findings corroborate with Medrinal et al. [27] who performed a cross-over study in 19 patients undergoing four types of intervention: passive lower limb exercises, passive lower limb cycle ergometry, quadriceps electrical stimulation, and quadriceps electrical stimulation associated with passive lower limb cycle ergometry and evaluated the physiological effects for the four types of intervention. They concluded that passive exercise, passive cycle ergometry and quadriceps electrical stimulation are considered low intensity activities and induce low levels of muscle work, and that the only therapy that was able to increase cardiac output and produce sufficient muscle work was quadriceps electrical stimulation associated with passive lower limb cycle ergometry.

Confronting our results, Monteiro and Sobral Filho [28] evaluated the physiological effects that physical exercise can have on body systems, especially the cardiovascular system. They stressed the importance of the physiological responses that regular exercise can promote, and that in blood pressure levels were reduced within the first hours after an exercise session. This divergence of results can be explained by the intensity of the exercise developed in our study, as well as the cardiovascular stress caused by passive cycle ergometry, which is very small, therefore not being sufficient to cause changes in blood pressure levels.

Freitas et al. [29] analyzed the effects of passive mobilization on acute hemodynamic responses and showed an increase in myocardial oxygen uptake or uptake (mVO2), double product and HR when evaluated at rest and after mobilization, although it did not present alterations that could harm the patient, this acute response after exercise with the elevation of some parameters is considered physiologically normal. Similar to Freitas's, Savi et al. [30] assessed the hemodynamic and metabolic effects of passive lower limb movement and observed only increased oxygen uptake and mixed oxygen saturation (SvO2), considering that increased 02 demand during exercise could contribute directly to a decrease in $\mathrm{SvO2}$.

Pires-Neto et al. [31], when actively using the cycle ergometer in MV patients, analyzed hemodynamic 
parameters (RR, HR, PA, Sp02), modified Borg dyspnea scale and a questionnaire containing five questions. After 5 minutes of exercise with active cycle ergometer, HR, RR and Borg values increased. Exercise with active cycle ergometry in the ICU slightly increased HR and RR, and the sensation of dyspnea, which is considered a normal response to exercise. Once again, these results may differ from our findings, as the use of active exercise during cycle ergometry is what distinguishes our intervention by the intensity and duration of the exercise.

This study has positive points as it is one of the first in the literature to evaluate cardiovascular and respiratory mechanics changes caused by a passive cycle ergometry session in mechanically ventilated patients. The limitations of this study include the small sample size and the impossibility of assessing heart rate variability.

\section{Conclusion}

By analyzing the effects caused by passive cycle ergometry in critically ill patients under MV, our study did not show any cardiovascular and respiratory mechanics alteration that could make its use impossible or cause any kind of injury. Therefore, this therapy has been shown to be safely and effectively used in clinical practice and can be applied without harming critically ill patients. However, it is essential to understand the beneficial effects and repercussions of exercise according to its load intensity, which is essential for exercise prescription for these patients.

These results reinforce its viability in preventing future complications related to ICU immobilization and muscle weakness in mechanically ventilated patients.

\section{References}

1. Denehy L, Lanphere J, Needham DM. Ten reasons why ICU patients should be mobilized early. Intensive Care Med. 2017;43(1):86-90.

2. Burtin C, Clerckx B, Robbeets C, Ferdinande P, Langer D, Troosters T, et al. Early exercise in critically ill patients enhances short-term functional recovery. Crit Care Med. 2009;37(9):2499-505.

3. Schweickert WD, Pohlman MC, Pohlman AS, Nigos C, Pawlik AJ, Esbrook CL, et al. Early physical and occupational therapy in mechanically ventilated, critically ill patients: a randomised controlled trial. Lancet. 2009;373(9678):1874-82.
4. Routsi C, Gerovasili V, Vasileiadis I, Karatzanos E, Pitsolis T, Tripodaki E, et al. Electrical muscle stimulation prevents critical illness polyneuromyopathy: a randomized parallel intervention trial. Crit Care. 2010;14(2):R74.

5. TEAM Study Investigators, Hodgson $\mathrm{C}$, Bellomo R, Berney S, Bailey M, Buhr H, et al. Early mobilization and recovery in mechanically ventilated patients in the ICU: a bi-national, multi-centre, prospective cohort study. Crit Care. 2015;19:81.

6. Nydahl P, Ruhl AP, Bartoszek G, Dubb R, Filipovic S, Flohr HJ, et al. Early mobilization of mechanically ventilated patients: a 1-day point-prevalence study in Germany. Crit Care Med. 2014;42(5):1178-86.

7. Connolly BA, Mortimore JL, Douiri A, Rose JW, Hart N, Berney SC. Low levels of physical activity during critical illness and weaning: the evidence-reality gap. J Intensive Care Med. 2019:34(10):818-27.

8. Berney SC, Rose JW, Bernhardt J, Denehy L. Prospective observation of physical activity in critically ill patients who were intubated for more than 48 hours. J Crit Care. 2015;30(4):658-63.

9. Jolley SE, Moss M, Needham DM, Caldwell E, Morris PE, Miller RR, et al. Point prevalence study of mobilization practices for acute respiratory failure patients in the United States. Crit Care Med. 2017;45(2):205-15.

10. Parry SM, Knight LD, Connolly B, Baldwin C, Puthucheary $\mathrm{Z}$, Morris $\mathrm{P}$, et al. Factors influencing physical activity and rehabilitation in survivors of critical illness: a systematic review of quantitative and qualitative studies. Intensive Care Med. 2017;43(4):531-42.

11. Amidei C, Sole ML. Physiological responses to passive exercise in adults receiving mechanical ventilation. Am J Crit Care. 2013;22(4):337-49.

12. Forton K, Motoji Y, Deboeck G, Faoro V, Naeije R. Effects of body position on exercise capacity and pulmonary vascular pressure-flow relationships. J Appl Physiol (1985). 2016;121(5):1145-50

13. Kovacs G, Herve P, Barbera JA, Chaouat A, Chemla D, Condliffe R, et al. An official European Respiratory Society statement: pulmonary haemodynamics during exercise. Eur Respir J. 2017;50(5). 
14. Trinity JD, Lee JF, Pahnke MD, Beck KC, Coyle EF. Attenuated relationship between cardiac output and oxygen uptake during high-intensity exercise. Acta Physiol (Oxf). 2012;204(3):362-70.

15. Gormley SE, Swain DP, High R, Spina RJ, Dowling EA, Kotipalli US, et al. Effect of intensity of aerobic training on VO2max. Med Sci Sports Exerc. 2008;40(7):1336-43.

16. Hickmann CE, Roeseler J, Castanares-Zapatero D, Herrera EI, Mongodin A, Laterre PF. Energy expenditure in the critically ill performing early physical therapy. Intensive Care Med. 2014;40(4):548-55.

17. Chiang LL, Wang LY, Wu CP, Wu HD, Wu YT. Effects of physical training on functional status in patients with prolonged mechanical ventilation. Phys Ther. 2006;86(9):1271-81.

18. Jerre G, Silva TJ, Beraldo MA, Gastaldi A, Kond C, Rudder F, et al. Fisioterapia no paciente sob ventilação mecânica. J Bras Pulmonol. 2007;33(2):142-50.

19. França EET, Ferrari F, Fernandes P, Cavalcanti R, Duarte A, Martinez BP, et al. Physical therapy in critically ill adult patients: recommendations of the Department of Physiotherapy of the Brazilian Intensive Care Association. Rev Bras Ter Intensiva. 2012;24(1):6-22.

20. Patel BK, Pohlman AS, Hall JB, Kress JP. Impact of early mobilization on glycemic control and ICUacquired weakness in critically ill patients who are mechanically ventilated. Chest. 2014;146(3):583-9.

21. Koch SM, Fogarty S, Signorino C, Parmley L, Mehlhorn U. Effect of passive range of motion on intracranial pressure in neurosurgical patients. J Critical Care. 1996;11(4):176-9.

22. França EE, Ribeiro LC, Lamenha GG, Magalhães IKF, Figueiredo TG, Costa MJC, et al. Oxidative stress and immune system analysis after cycleergometer use in critical patients. Clinics. 2017;72(3):143-9.

23. Cordeiro AL, Barbosa AFN, Leitão LP, Araújo PAS, Carvalho S. Hemodynamic effects of cycle ergometer training in postoperative cardiac surgery patients. DERC. 2014;20(3):90-3.
24. Pinheiro AR, Christofoletti G. Motor physical therapy in hospitalized patients in anintensive care unit: a systemic view. Rev Bras Ter Intensiva. 2012;24(2):188-96.

25. Machado AS, Pires-Neto RC, Carvalho MTX, Soares JC, Cardoso DM, Albuquerque IM. Effect that passive cycling exercise have on muscle strength, duration of mechanical ventilation, and length of hospital stay in critically ill patients: randomized clinical trial. J Bras Pneumol. 2017;43(2):134-9.

26. Kho ME, Martin RA, Toonstra AL, Zanni JM, Manthleiy EC, Needham DM, et al. Feasibility and safety of in-bed cycling for physical rehabilitation in the intensive care unit. J Crit Care. 2015;30(6):e1-5.

27. Medrinal C, Combret Y, Prieur G, Robledo Quesada A, Bonnevie T, Gravier FE, et al. Comparison of exercise intensity during four early rehabilitation techniques in sedated and ventilated patients in ICU: a randomized cross-over trial. Critical Care. 2018;22(1):110-7.

28. Monteiro MF, Sobral Filho DC. Physical exercise and blood pressure control. Rev Bras Med Esporte. 2014;10(6):517-9.

29. Freitas ERFS, Bersi RSS, Kuromoto MY, Slembarski SC, Sato APA, Carvalho MQ. Effects of passive mobilization on acute hemodynamic responses in mechanically ventilated patients. Rev Bras Ter Intensiva. 2012;24(1):72-8.

30. Savi A, Maia CP, Dias AS, Teixeira C. Hemodynamic and metabolic effects of passive leg movement in mechanically ventilated patients. Rev Bras Ter Intensiva. 2010;22(4):315-20.

31. Pires-Neto RC, Pereira AL, Parente C, Sant'Anna GN, Esposito DD, Kimura A, et al. Characterization of the use of a cycle ergometer to assist in the physical therapy treatment of critically ill patients. Rev Bras Ter Intensiva. 2013;25(1):39-43.

Received in 04/02/2019

Recebido em 02/04/2019

Recibido en 02/04/2019

Approved in 07/22/2019 Aprovado em 22/07/2019 Aprobado en 22/07/2019 